\title{
The Scenic of the Problematic Memory in the Novel: There in the Glen of the Wind
}

\author{
Hadeel Abdulrazzaq Ahmed, PhD \\ Arabic Language Department \\ AL Hikma University College \\ Baghdad - Republic of Iraq
}

\begin{abstract}
The problematic character is an important element in the narrative text, where antagonisms are mutually reinforcing, conflict is achieved, the problematic character Lives a selfdivision between living a normal life and exercising its private life, or to be Fused in amidst its Social reality, believing in that life's values and principiles. It is a character that Acts by its own motivation, Seeking to Change But often Eventually sets back to its own private world. This character is demonstrated clearly in the novel ( There In The Glen Of The Wind ) by Iraqi novelist Abdul Rahman Majid al Rubaie, through the character of (Hassan al Zaidi), as it is a problematic character, filled with self-haunting and existential alienation, and communal (leaving home), and burdened with the human mind, and suffering loss identity, and the worsening of situation, the absolute and helplessness about the transitions, because of the dominance of a sense of inequality between it and the changes of its surroundings .
\end{abstract}

The writer's use of the narrator's (Complete Knowledge of Multi Selections), contributed to reveal conflicts of the problematic character, through introspection and awareness, and documenting its memory in a dramatic way, which dominated the general structure of the novel, creating a complete image of the character. We have not only heard it, but also seen it, which has made the element of inspiration realistically visible.

The story was presented directly as (Hassan) lived it, and as reflected in his consciousness, and presented ideas and visions and feelings as formed by the curriculum , the novel appeared as if without a narrator, documented by the problematic consciousness and memory, scenes of psychological ruins of the individual and society, and the country under the influence of wars and authoritarian repression, was a living reflection , revealing the opposing conflicts between awareness of the crisis and the inability to find salvation from them .

\section{Keywords}

Novel, Glen Wind, art, Arabic literature, criticism, Scenic problematic memory. Problematic hero.

\section{INTRODUCTION}

The novel has the most literary and artistic form of the society and the expression of its issues and the problems of its members; several artistic, intellectual and aesthetic elements that qualify it to carry out cultural and communicative functions that may fall short of the other literary genres .

It is more than giving a complete picture of the world and the age mechanism [1] . In the novel, contradictions are revealed, and conflicts are revealed in all their forms, whether those that are with the self, or with society in its values and its members, Which made it a matter of receiving interest and curiosity in the modern era, As a wider place, and more open space The possibility of asking existential questions, searching for them and their answers.

The theme of our research seeks to raise questions, and the search for the answers, Through diving in the depth of the text, to explore and interrogate its features, as the text of a dialectic based on highlighting the image of the world through negative problematic figures, contributing to introspection and awareness, and its thoughts, internal feelings, and revealing its vision of the universe, in the slow march of the narrative, embodied if the individual lives in a world that begins with problems and does not end.

It is known that the narrative text must be problematic, and is full of conflicts and contradictions, which make the text full of intellectual movement and controversy, and raises questions and curiosity to explore the elements of creativity, especially when the creator of the first columnists and the pioneers of the art of story and novel in Iraq and the Arab world In this novel, Al-Rubaie created a disturbing picture of society and a path filled with chaos and ruins through his deep understanding of human problems, ideological conflicts, and the monitoring of self-attitudes towards society and its transformations.

\section{PROBLEMATIC CHARACTER / PROBLEMATIC HERO.. CONCEPT AND IMPLEMENTATION IN THE ARAB CRITICISM}

The novel is still the source of the narrative imagination and its main center. It is not without contemporary literary work of this format in its composition, and although the novel has lost some of its formations and its components, it urges the pace of the new novel, however, the novel especially Arabic, still clings to the human being as the axis of this world, despite all attempts to distort, and destabilize his status, and make it discipline, but that the person himself, and this has been demonstrated for centuries in the formulations of Aristotle, the artistic character as a secondary product in narrative work for the privileges that the personal received at the hands of the book of the novel realism [2] .

And the term (Problematic Character) has Multiple Dimensions, diverse Significance, had limited use in the Arabic criticism speech, although the character in the novel has been discussed a lot and was of the utmost importance through its new analysis methods [3] Much has been said about its construction, forms and nature, whether it is a representation of vivid and realistic images, or as an embodiment of patterns of social and cultural awareness. Personality is the psychological counterpart of the concept of culture [4], Through its behavior and the considerations of its construction and composition, the cultural context of a particular society or group is manifested. In other words, it is 
a conceptual construct that embodies models of the behavior of the prevailing culture [5] .

And the essence The problem is determined in the character splitting on itself, between living its own life or blend in with society and believe in its values and principles, as it is a character that acts by its own Motivation seeking change by means of appeasement, but often sets back to its own world eventually [6] .

The problematic hero is the one who holds authentic values that he wants to fix in his frustrated and debilitating world, but he fails to do so, because he does not realize that reality is greater than he is, or that he realizes this reality and escapes it to involve himself or to reconcile with him and adapt And merge into it. Hence, the problematic hero combines negative and positive, and hesitates between self and subject. On the one hand, it carries authentic positive values, and at the same time fails to change its own deteriorating reality, so the conflict ends up either into the reckless naïve adventure to escape from reality to itself or to reconcile and learn from reality experiences [7].

\section{THE TITLE OF THE NOVEL AND IT $\square$ S PROBLEMATIC}

There in the Glen of the wind, is one of the novels of the great Iraqi writer Abdul Rahman Majid al-Rubaie, issued in 2011 by the House of Arabic inscriptions. At first sight , and before the arrival of its worlds, we encounter its title. Why did the writer choose the place of the wind for his novel? And any attributes that suggests that by this title?

The title of the novel gives away the hidden features of the untold story and related characters, and the crisis of the long remote way overseeing its emptiness at the end of the day and expressing the spirit barren of these characters, and their dreams that are infanticided before birth "single crude and collected Glens, and crude is the wide road between two mountains, but Look, there Set of mountains, so it is true to say about the place the wind is blowing ... and the fug is immature of the fruit " [8]

So al Rubiei in this novel - as in other novels - depends on (human) and his related miseries, shows this man in his world the novelist complex of diets, desires, and suppressions, and contradictions, feelings, which hide themselves behind a barricade. So al - Rubaie's task falls on revealing this human's problematics and we mean with these problematics that they are a complex system of relationships which are woven into a particular thought of several crises . Problems are interdependent and interrelated, fierce personality and driving events, drive the direction of the destinies of the characters towards (non - feasibility), so that it can not be solved individually, It is only theoretically resolved under a general solution, all of them [9] .

This is what is revealed by the paths of detection and characterization of characters, showing the personality in the novel in the hands of the research is intertwined with the homeland, and linked to the transformations, which flourish when it flourishes, and share the devastation wherever it is, as appears in this text, " while Hassan put his back to the chair reclining, his eyes scour street which is packed with cars and people moving, however, the women passers by had their share of his confused looks. He did not have those first vigor that was in those mighty old days, he felt as if there were cursed cats in his blood. Then the destruction of Iraq came to extinguish all His roots, even for those women who absorbed him in the first weeks For being in Tunisia " [10] . So al
Rubiei did not present a typical normal human being, but revealed a man wonky under the movement of complex circumstances, embodied through the argument that the basis of the true human nature can not be achieved in the quiet normal life, which human witnessed by according calm conditions, as not showing itself the humanitarian nature of the characteristics, in times of prosperity or regular diary, because their origins are reflected in times of crisis, and spiritual and moral imbalances [11] .

\section{PROBLEMATIC IDENTITY AND PSYCHOLOGICAL ALIENATION}

The novel has multiple themes that are problematic in nature. They contradict the authority of the audience in the text, and the most prominent of these themes is the "obsession with human alienation" in all its manifestations. The sense of alienation within society, and the inability to influence it, the fading of the individual 's personality, and his sense of Marginalization within the maze of life, dominates the landscape of the world of this novel, and stands out clearly through the personality of (Hassan Zaidi), Iraqi painter resident in Tunisia, with a Palestinian passport and a residence, for his work with members of the Palestine Workers' Union, designed for a magazine of the Union that moved to Tunisia after the 1982 Beirut invasion.

The writer deliberates to make (Hassan) the focus of the novel and its center, as from and within him the problematic character is embodied and manifestations of the reality of the Iraqi human radiate and the problem of existence, and the fragmentation of identity are lost in the midst of internal and international political conflicts, as it seems clear in his interview with (Fatin) "I wonder now: What fates connect me to this city? This country? I leave it and then I find myself returning to it, this time I do not know how long I will stay in it? Beyond this where will i go? To a besieged Iraq with a strict grip of a heavy system? to a family who sold everything just to eat their daily bread ... I am now a Palestinian, says my paper at the Interior Ministry which is written on my residence card, how can this be and I am Iraqi to the core? " [12]

Hassan is one of the defeated, shaky, conflicted, and fragile characters. His personality is intertwined with two contradictory movements, the first pushing him towards consciousness and the other taking him toward the subconscious. The first tries to keep him out of the circle of surrender and failure, while the second stubbornly refuses to escape the enclosure of that narrow and closed on itself circle

. From the beginning until the end, even though it is true, despite all internal conflicts, contradictions, and conflicting antagonisms over the power of hegemony, in order to change and move away from the reality imposed on him and his oppressor. However, attempts also fail because they are weak attempts large and conquer, there is no parity between the opposing and conflicting values, so the character surrenders as always, and stripped of any weapons of hope no matter how simple, because the transition to the positive side contrast was a transition powerless from the beginning, as reflected clearly in his speech to the glamorous "I am like an accurate thermometer, mercurial that moves up and down, does not settle and here it is today at the moment you might see as strange to me and I am a drowsy braggart. I hold a lot of joy but a prisoner's joy, howcan I launched it and the homeland is being slaughtered? People do not find anything to eat except with ration coupons given monthly by the state to the citizens as if they were in refugee camps and not in their homeland " [13]. 
And the non - equality dominates which is felt by Hassan ,between him and his surroundings, generating in the same absolute sense of total helplessness about the variables, and to no avail of everything, starting with the art which the state transformed in favor of its ideology, through love (his relationship with Fatin), sex (his physical relationship Radiah) "Hassan felt then that she is close to him in her despair and loneliness despite having a family and a job " [14] , also through political party work, and faith in a certain ideology, such as the communism that he believed in and left as a loser after sensing the conflicts of their members and their betrayal of some. His emotional and sexual exploits are only a form of inspiration for salvation from disappointment and darkness of fate, his relationship with the world suffers from unrest and absolute inconsistency. All this made Hassan's character a victim of expatriates with a strong dialectical relationship. The first is the psychological framework: the alienation of the self, the fragmentation of concepts of values, the struggle of the remains of the depths, and the other is the alienation of society, whether manifested by the inability to interact and integrate With the community; to widen the cultural, ideological and behavioral gap with its members, or by leaving the country and migrating from it, the negative relations are created within the narratives of the narrative, fueling various elements of internal conflicts: (between the personality itself) and external: And the other, whether as a member or a whole society, as in this text, for example, Hassan in his distracting walk seemed to speak to himself, as his lips rebelled against him and moved as he thought and conversed himself: "I must blow the festers of the depths, take out

all the pus, Faces, what I loved especially. Those that do not turn off nostalgia, or those that I hate and I do not want to see, faces run by the opportunism of the pocket, and I was always associated with large rats pregnant, movements filled with suspicion, and heads moving right and north are crushed as if they eat everything above the ground, Like wires. "He stops to contemplate the buildings that have been abandoned and the time has come to demolish them. The alley loses its character and leaves the smell of time " [15] .

\section{TECHNIQUES OF SCENOGRAPHIC NARRATIVE MEMORY}

The narrative techniques used by the writer combine to shed light on Hassan, to highlight the problematic aspects of his reality and his suffering, and despite the presence of more than one narrative style in the presentation and presentation of events; but combined they only detect the personality of Hassan. The chapters of the novel are narrated by the narrator with the selective multivariate / multi-selectivity ( multipile selective omniscience), (According to Norman Friedman's classifications), which he knows As: the narrator who completely disappears And excluded in favor of the presence of his characters, there is no narrator left here to provide events, but the story directly through the minds of the characters, and as it is lived by them, and reflected in their consciousness, In front of the receiver is (scenic) Fully, because the narrator here shows us the internal situations and emotions of the characters And dramatize it, staring at the minds to tell what is going on there, and the advantage of this narrator that it is not placed in the consciousness of one person only, but appears in the consciousness of most characters of the novel, it provides the ideas, visions, feelings, as they occur in turn and are embodied in their consciousness, the recipient continues to develop the events of the text through personal awareness, so the knowledge of the narrator here is basically the knowledge of this person And awareness of it [16] . In addition, the narrator, the provision of some chapters are also through Faten Abdul Aziz listed (In selfnarration with the conscience of the speaker) so they are together a tool to detect internal awareness of Hassan, and his thoughts blundering, as a personal problem defeated, carrying as of antonyms in a world that only gives him disappointment.

The selection of the narrator (Total knowledge of multiselections) intelligently from the author, so that these kinds of narrators embraces personal consciousness, and reveals to us directly without mediation, with all internal conflicts, and gestures, and its observations, which brings us an important scenographic and dramatic side, , dominates the general structure of the novel, creating an integrated and theatrical picture of the character which we not only hear but see as well, which also achieved the illusion element of personal realism. So the tale is presented directly as it is lived by (Hassan) and as reflected in his consciousness, and ideas, visions, feelings are made up gradually and presented, so the novel seems as though it has no narrator, as in this text, for example, "Hassan began to recover surpassing the rubble of his soaring grief, he was going through Rabi'a al Adawiah street back and forth and often sigh in altitude and often stopped by the the sound of horns of flying cars like the sludge race. sometimes he would move his arms to breathe deeply as he is in the glen of the wind, a restless glen, and many times he repeated within himself that the popular memory invented this name in a strange description of the place, since one does not know often where the wind blows? As if blowing from all sides, collide and then disperse, and then gather ... The wind of the glen hit him so his hair blew wildly, and he tried to straighten it the wind keeps blowing to fill his eyes with heavy dust like crushed stone atoms, it is not the same dust of Iraq that comes from deserts and people call it (Toz) " [17]. So the narrator here made the recipient conceive the text through the events of Hassan's memory and awareness while casting its focus on the inner world of his reservoirs, articulating his thoughts, and adopting his vision and his observations, and in compatibility with him.

Mainly employing the perspective of the personality, behind it is the progressive development of the novel, and its transition in the midst of several transformations of documentary realism (where characters are images of society) to the novel of the personal formula (where society is merely a background curtain of personality), the life events flow smoothly, while exploiting this tension clearly, and employs fully in the novel version of the personality [18] because they are based primarily on confrontation between the person and society, or between the person and himself. On this basis, the book of the novel realized the importance of the rebellion on the traditional axis and the transition from the broad narrator or the so-called narrator to the observed narrator or to the observed personality or to the central character or to the combination of all these manifestations [19] .

This type of narration directly contributed to the spectacular documentation to the confused memory of (Hassan), heaving with the devastation caused by wars, political transitions, bloody coups and conflict authoritarian in Iraq, and his problems of all this, so Hassan is a problematic character with distinction, he is alternating between (self) and (reality), it lies in the same authentic values, dreams and goals of seeking them, but it collides with reality TWILIGHT, making it defeated in front of his ferociousness and its challenges, incapacitate change what surrounds the tragedies no longer his own thing, "it is all over, Iraq is destroyed, And they beat 
him with a deep hatred, and began the enthusiasm in the dimness, in the brightness of the Arab earth And the scars on the conscience will be cured by forgetting ... He went out leaving everything to them, even though the beauty that remained alive does not carry on ... The war brought back the land and the people to the Middle Ages ... They left nothing but bombarded it,Hassan was not there when all this happened but when he saw the pictures of the bombing it felt as if the bombing was on his body, although he is far away " [20] .

(Hassan) carries authentic values which he tries to instill in the society in which he lives, but he suffers disappointment and failure when he discovers his degenerate reality, where the system of values disintegrate, and the false materialism exchange is in control, he can not change the reality despite all his attempts, which seperates him from his community, and makes him belong to an excessive extent of his individuality and his self, which works to achieve them away from the pressure and guidance of the group. It also exacerbates his alienation from himself and from others when his external actions fail to satisfy his inner desires.

Thus, the novel documented through the awareness of the problematic character and its memory, scenes of psychological ruin of the individual and society, and the nation plagued by war and repression of authoritarian, was a mirror to monitor the dialectics of conflict and schizophrenia between (awareness and practice), there is (awareness of total) crisis, offset by (absolute deficit) for (practice) termination , As it seems clear in this text, " that damned ulcer that came after seeing the face of Schwarzkopf hateful American leader inflated hatred and hatred, and he speaks with boast from satellite TV about his victory as if he had won in a third world war and not a third world country " [21] .

Finally, al-Rubaie presented his characters as in most of the of his novel worlds, in the framework of the negative hero full of problematics, which begins not existentially and sensed the absurdity of his existence, but ended also [22] The sense of pessimism, self-sufficiency, and tight psychological closure is what Hassan's character built along the length of the novel, to prevent any area of change. The structure of eternal and absolute silence dominated it, despite the presence of several elements of antagonism. I have tried collectively to create worlds filled with movement, conflicts, between the same personality at times, and between personality and society at other times. So Hassan tries to move, reject his imposed reality and seek to change it, moving until he exhausted his powers, and then in the end he lives completely resigned to disappointment and failure as a whole..

\section{CONCLUSION}

Finally, in the midst of the struggle of the literary races and the acquisition of some of them in the forefront of production and interest, the novel remains the most representative of the real relationship between man and himself on the one hand and between man and society on the other. (This is evident in the novel ), As Al-Rubaie highlighted the images of conflict with self and society through (Hassan's) memory in a spectacle, making reality with its contrasts a background for his novel world, and a stage on which the characters stand.

We have found that despite (Hassan's) pursuit to overcome his problematical reality, the attempts always ended in failure , and included in the absurd format and uselessness, because it 's achievements are incomplete, in existence surrounded with tragedy from every side, so he lacked communication and integration with society, to widen the gap between him and Members of the perimeter. He is a character emerged from the midst of the current events, to reflect the size of the diverse forms of conflict both economic or social or moral, so he is not more than a product of reality that has lost its originality and values.

The novel expressed through this character, the estrangement between the ( self ) and ( the other) in an ideal way, whether this (other) was a person or a counter idea, the novel fuels reservoirs of psychological anxiety, stimulates memory to evoke scenes and memories, and to stay inside and not to leave, so it becomes a reality imposed on the character unable to escape from it and victor over it, so they surrender to this reality.

The techniques of narration, and the artistic and structural methods adopted by the writer, contributed to the illumination of the world of the character and its surroundings, and reveal the manifestations of its inner consciousness and its meanings. The narrator's narration method came with a comprehensive knowledge of multiple selections to make the recipient within the personal consciousness and in direct confrontation with its thoughts and feelings. The characteristics of scenic narration are revealed through the annals of the memories of the problematic crisis.

\section{REFERENCES}

[1] See: The Theory and Evolution of the Novel, George Lukacz, Translation and Presentation: Nazih al-Shufi, 1987, p. 26.

[2] See: The New Novel, Its Constructions and Transformations, Muhammad Daoud, Ibn al-Nadim for Publishing and Distribution, Algiers, Dar al- Rawafad alThawafiyya - Publishers - Beirut, 1, 2013, pp. [3] See: Techniques of Personal Presentation in the Iraqi Novel, A Technical Study, Ather Adel Shuai, House of Public Cultural Affairs, Baghdad , pp. 27-35, 46- 58, 66-81.

[3] Seen: Typical Character in TV Drama, d. Saleh AlSahan, Adnan House and Library, Baghdad, 1, 2014 , p. 53.

[4] See: Society and Personal Culture, d. Ali Abdul Razzaq Chalabi, Faculty of Arts, Alexandria University, Egypt, 1998 , p. 252.

[5] See: Hero in the Palestinian narrative in Palestine from 1993 to 2002, a message MA, University of Success National, College Studies graduate - Nablus, 2005 , S7072.

[6] See: Problematic Character in the Narrative Narrative by Naguib Mahfouz, Sara Iman Sayed Hussein, Master Thesis, Fayoum University, Faculty of Arts, Department of Arabic Language and Literature, 2012 , pp. 7-9.

[7] There is in the glen of the wind, Abdul Rahman Majid alRubaie, House of Arabic inscriptions - Tunisia, 2011, p. 112.

[8] See: We and Heritage, Contemporary Reading in Our Philosophical Heritage, Muhammad Abed Al-Jabri, Dar al-Tanweer for Printing and Publishing - Casablanca, 4, 1985 , p. [10] There in the glen of the wind, p. 37.

[9] See: The Problem of Man in Dostoevsky , Study of Philosophical Practice in the Artistic Framework, Jassim Bedaiwi, Ibn al - Nadim Publishing and Distribution Algeria, Dar reaches Cultural - Publishers- Beirut, i 1, 2015 , p. 34. 
[10] There in the glen of the wind , p. 114. [13] Ibid .,Pp. 7374.

[11] The same source, p. [15th] The same source, p. 65.

[12] Consider: statements and representations and illusions, a study in modern Arab criticism, d. Yahya Aref AlKubaisi , House of Public Cultural Affairs, Baghdad, 2009 , pp. 60-61.

[13] See also: The narrative term in the modern literary criticism, d. Ahmed Rahim Karim Al-Khafaji , Dar Safa for Publishing and Distribution - Amman, Dar Al-Sadeq
Cultural Foundation - Hilla, 2012 , p. 189. [17] There in the glen of the wind, p. 180 .

[14] See: drama novel, a study in the manifestations of the modern Arab novel, d. Basem Saleh Hameed, Public Cultural House , Baghdad, 2012, 174. [19] See: stream of consciousness in the modern novel, Robert Humphrey , translation: d. Mahmoud al - Rubaie, 2, Dar al-Ma'arif, Cairo, 1975, p. 53. [20] There in the glen of the wind, p. 30.The same source, p. 170.See: Abdulrahman Majid Al-Rubaie and the negative hero 